Available online on 15.12.2019 at http://jddtonline.info
Open Access to Pharmaceutical and Medical Research
unrestricted non-commercial use, provided the original work is properly cited

Open- Access

Research Article

\title{
Efficacy of Colletotrichum gloeosporioides, potential fungi for bio control of Echinochloa crus-galli (Barnyard grass)
}

\author{
C. Nandhini, P. Ganesh*, K. Yoganathan, Deepak Kumar \\ Department of Microbiology, Annamalai University, Annamalai Nagar, Tamil Nadu- 608002, India
}

\begin{abstract}
A systematic field study was conducted in agricultural fields such as food crops, pulses, vegetable crops, oil crops and commercial crops to estimate infestation of Echinochloa crus - galli (barnyard grass), a common terrestrial weed belonging to family poaceae. The in vitro pathogenicity studies on barnyard grass were conducted using spore inoculum $\left(8 \times 10^{7} / \mathrm{ml}\right)$ of an indigenous fungus, Colletotrichum gloeosporioides. The pathogen was re-isolated from inoculated plants to fulfill Koch's postulates and confirmed its host specificity on barnyard grass. The disease by the isolate was critically analyzed and the results revealed that Colletotrichum gloeosporioides is a potential agent to biological control of barnyard grass. The results revealed that the pathogen causes significantly $(P<0.05)$ severe infection on host weed and destructs the weed population by leaf spot diseases. The findings of the research suggested that the isolate Colletotrichum gloeosporioides is highly virulent and host-specific, and recommended for further studies as a promising biocontrol agent against barnyard grass weed.
\end{abstract}

Keywords: Mycoherbicides, Barnyard grass, Colletotrichum gloeosporioides, Koch’s postulates

Article Info: Received 09 Oct 2019; $\quad$ Review Completed 18 Nov 2019; Accepted 24 Nov 2019; Available online 15 Dec 2019

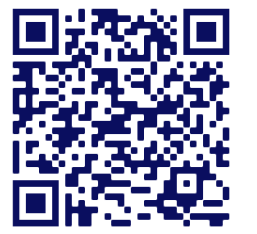

\section{Cite this article as:}

Nandhini C, Ganesh P, Yoganathan K, Kumar D, Efficacy of Colletotrichum gloeosporioides, potential fungi for bio control of Echinochloa crus-galli (Barnyard grass), Journal of Drug Delivery and Therapeutics. 2019; 9(6-s):72-75 http://dx.doi.org/10.22270/jddt.v9i6-s.3751

P. Ganesh, Department of Microbiology, Annamalai University, Annamalai Nagar, Tamil Nadu- 608002, India

\section{INTRODUCTION}

Echinochloa crus- galli L., commonly known as cockspur or cockspur grass, water grass and barnyard grass belongs to the family poaceae, causes high yield loose in different agricultural crops. In recent years, herbicide resistant biotypes of barnyard grass were reported (Fu et al. 2001; Maneechote 2003). It is essential to develop some new alternative tactics for the long term management of barnyard grass in the future. It reduces crop yields and cause forage to fail by removing up to $80 \%$ of the available soil nitrogen. Barnyard grass commonly occurs throughout tropical Asia and Africa in fields and along roadsides ditches, along railway lines and in distributed areas such as gravel pits and dumps. It occurs in all agricultural regions. Echinochloa crus-galli (Barnyard grass) is one of the most troublesome weed species in rice production. It is well adapted to wet soils, and is common in both temperature and tropical crops, being reported in 36 crops in over 60 countries (Holm et al., 1977). Barnyard grass (Echinochloa crus-galli) is a major weed in lowland rice cultivation in many parts of the world. The most widespread and economically important species from the genus is E. crusgalli, or barnyard grass (Maun and Barrett 1986) which has been reported to reduce the rice yield by $5-72 \%$ (Kuan et al., 1990).

ISSN: 2250-1177
In Malaysia, the grass is mainly controlled by chemical herbicides which have contaminated the environment (Leong et al. 2007), it also affected the microorganism communities (Chen et al., 2009) and led to resistant biotypes of the weed (Sangakkara et al., 2004). Biological control has therefore, been identified as an alternative method to avoid the negative impacts of chemical herbicides. Echinochloa crus galli spreads only by seed, and its high capacity for seed production allows large populations to rapidly establish. Seeds can be dispersed by check, water or as a contaminant in soil, seed crops, and on agricultural machinery (CABI, 2015). The origin of Echinochloa crus - galli remains obscure but it probably native to tropical Asia (USBA-ARS, 2014).

According to (CAB 2015), Echinochloa crus- galli has a distribution extending from Northern Europe, to the subtropics and to tropical. The awareness on conservation of biodiversity and control of environmental pollution demands the exploitation of microorganisms as pets and weed control agents. Especially plant pathogenic fungi are now emerging as an effective and eco- friendly alternative to conventional methods of weed control (Charudattan 1991). Devine and Collego, are used commercially in the United States to control respectively the milk weed vine, Morrenia odorata in citrus groves and northern jointvetch, Aeschynomene virginica, in rice and soya bean fields 
odarkansas and high borning states (Bowers 1986; Templeton et al.,1984). Zhang (1996) found that E. monoceras, at a rate of $10^{7}$ spores/ ml, killed E. crus-galli.

Biological control of weeds has more advantages over mechanical and chemical methods, and can be specific to the target weed and does not lead to residue problems and accumulation of toxic pollutants in the soil or underground water (Tebeest et al., 1992). Seeds with a positive tetrazolium test carsenal of phytotoxins which recovered only from were summed with germinal seeds to give viable seeds. Culture filtrates as Colletotrichnins by $C$. nicotianae and viable seeds were then expressed as a percent of total $C$. capsici; Colletopyrone produced by $C$. nicotianae seeds to arrive at a percent viability. In some cases, Aspergillomarasmine produced by $C$. gloeosporioides viability was also expressed as a percent of and Ferricrocin produced by C. gloeosporioides (Pajon et al., 2003; Boyette et al., 2007).

\section{MATERIALS AND METHODS}

\section{Field study and samples collection}

The field observation on invasion of barnyard grass was in different crop classifieds as food crops, pulses, and vegetable crops at delta District. Diseased leaves of Echinochola crus galli weed were collected in delta districts of Nagapattinam, Thanjavur and Thiruvarur in the year 2017-2019. Infected plants were collected in sterile polythene bags and brought to the laboratory for the study of symptoms isolation, identification and pathogenicity test of the pathogens involved. Specimens were pressed, dried and kept as herbarium record, bearing details like name of the host location, date of collection etc. The disease symptoms on leaves and stems were examined as round to oval straw colored spots with maroon margins. The diseased plants and propagule were collected in sterilized polythene bags and brought to the laboratory for the study of symptoms, isolation and pathogenicity test of the organism (s) involved in leaf spot disease. The disease symptoms on leaves and stem were critically observed and studied in Microbiology laboratory, Department of Microbiology, Annamalai University, Annamalainagar.

\section{Isolation Identification and Subculture of fungi pathogens}

The diseased leaves were washed thoroughly in running tap water to remove soil particles, and the infected portions of the leaves were cut into $1.0-1.5 \mathrm{~cm}$ fragments. The pieces were surface sterilized by $70 \%$ ethyl alcohol for 1-2 min and then rinsed in sterile distilled water for three to four times. These fragments of leaf bits were transferred to Czapek dox agar (CDA) and potato dextrose agar (PDA) plates supplemented with $3.7 \mathrm{mg}$ of streptomycin sulfate and 2.5 $\mathrm{mg}$ of chloramphenicol per liter of medium. The antibiotics wear added to prevent bacterial contamination of cultures, under sterile conditions in an inoculation chamber. After inoculation, plates were incubated at $27 \pm 2^{\circ} \mathrm{C}$ for 21 days on a $12 \mathrm{~h}$ light/dark photoperiod. The isolates were purified by separation of small aerial mycelia fragments with inoculation loop on new culture plats in the initial growth of fungal colonies. The stock cultures isolates were prepared using mono culture (single conidial culture) and stored at room temperature as slant cultures on PDA media. The isolates were examined by the staining techniques, and diagnostic characteristics of the isolates were examined under light microscope. Identification and taxonomic features of the isolates were made with help of the relevant literature (Simmonse et al., 1986; Mitchell et al., 1988; Aneja et al., 1998;; Aneja et al., 2000; Akhtar et al., 2013). The isolates were properly sub-cultured on PDA and CDA for further research and maintained in PDA slants at $26 \pm 2{ }^{\circ} \mathrm{C}$ in Microbiology Laboratory, Department of Microbiology, Annamalai University.

\section{Inoculum Production of Test Pathogen}

The young and well sporulated isolates of Echinochloa crusgalli were used for the assay of disease intensity at in vitro conditions. After 12-14 d of incubation, the spore suspensions were harvested from each culture by adding 20 $\mathrm{mL}$ of sterile distilled water and scraping of mycelium surface with a sterile glass rod or spatula. The resulting slurry of spores and mycelia fragments was filtered with 3-4 folded cheesecloth, and filtrate was taken into $250 \mathrm{~mL}$ conical flasks. Spore suspensions were centrifuged at 3,500 rpm for $20 \mathrm{~s}$ for purification of filtrated spores, and the optimum spore concentrations were enumerated using a haemocytometer. An aqueous conidial suspension $\left(8 \times 10^{7}\right.$ spores $/ \mathrm{mL}$ ) of the fungus was prepared and standardized with haemocytometer. An optimum concentration of Tween$20(0.02 \% \mathrm{v} / \mathrm{v})$ was added as wetting agent to the conidial suspension before application of the spore treatment of test plants.

\section{Inoculation of Test Plants}

Inoculations were made on young plants growing under greenhouse conditions up to spore treatment. The plants with young leaves (at 6-8 leaf stage) were inoculated with an optimal conidial suspension $\left(8 \times 10^{7}\right.$ spores $/ \mathrm{mL}$ spore inoculum $+0.02 \%$ Tween-20) of Echinochloa crus-galli by hand sprayer after sunset (between 6:00 pm and 7:00 pm) to avoid drying of the spores. After inoculation, leaves were enclosed with sterile polythene bags for $48 \mathrm{~h}$ to maintain $100 \%$ humidity for feasibility of the spore germination. Control plants were treated in the same manner, except that they were sprayed with sterile water $+0.02 \%$ Tween- 20 . The adjuvant

Tween-20 was applied as a wetting agent. After inoculation experimented, leaves were collected from both test plants (spore treated) and control plants (water treated) at 10 days of intervals to examine the virulence of pathogen. For in vitro experiments, both the control plants and test plants were maintained in five replicates, each contains 10 pots (Five plants per one pot). A total of 500 plants ( 250 control plants and 250 test plants) were maintained for each experiment.

\section{Measurement of disease intensity}

The intensity of disease was measured in terms of disease incidence (Wheder 1977) and disease severity (Chaube et al., 1991). The disease severity was examined at 10 days of interval, and the leaf spot disease was evaluated using standard area diagram of infected leaves. The quantitative data on disease severity were calculated using the analysis of variance, as following Balyan et al., (1986). For the estimation of leaf area diseased, the whole leaf surface area was considered as 100 , and thereby the infected area was determined by eye estimation for percent of disease index (PDI). ie. Disease severity disease intensity and severity were rated by visual observation, and the infected leaves were scored using a 0.5 scale rating system Ray et al., (2012). Using this rating system, a disease index (DI) was calculated per observation made at an interval of 10 days after treatment, for the assessment of disease severity individual leaf ratings were taken into an account until the death of weed 


\section{Disease intensity (DI)}

Inoculum was applied onto the test plants of Echinochloa cruss-galli within 2 hours of sunset to avoid drying and to allow for a natural dew period shortly afterwards. Plants were observed three days after treatment (DAT) for disease symptoms. The intensity of infection was determined visually, based on the initiation of disease and increase in disease area on the leaves, stems of test plants every day. The disease intensity of pathogen on test plants was determined using a score chart (-, no symptoms, a healthy plant; +, mild symptoms, a plant showing slight symptoms on $\leq 15 \%$ of the leaf area; ++, moderate symptoms, a plant showing definitely bigger patches of diseased areas on 16 to $59 \%$ of the leaf area; and +++, severe symptoms, enlarged lesions covering 60 to $80 \%$ of the leaf area) (Ray and Hill, 2012).

\section{RESULTS AND DISCUSSION}

\section{Identical characteristics of $C$. gloeosporioides}

The identification features of the isolates, such as colony diameter, color, texture, sporulation, the shape and sizes of conidiophores and conidia, were carefully studied. The causal agent of leaf spot disease of Echinochloa crus- galli was isolated from wild plants and simultaneously from test plants inoculated with spore suspension. The pathogenicity of the isolate was confirmed by Koch's postulates, and the host specificity of the pathogen was tested using repeated spore treatments and reisolation of causal agent. At maturity stage, the profuse radial growth and sporulation of a fungal pathogen were recorded, and the isolate was confirmed as $C$. gloeosporioides by microscopic study of mycelium, conidia and conidiophores. Inoculated leaf lesions yielded white colored colonies of $C$. gloeosporioides at initial stage on the surface of nutrient media. Subsurface mycelial growth was dense and dark on PDA. Sporulation was excellent at agar surfaces of CDA, and the moderate amounts of sporulation appeared on PDA. Significantly $(P<0.05)$ higher radial growth $(\mathrm{mm})$ of the isolate was recorded on PDA $(76.67 \pm$ $1.76 \mathrm{~mm})$, followed by on CDA $(70.67 \pm 1.76 \mathrm{~mm})$ on the 12th day. C. gloeosporioides often proliferates by means of a secondary conidiophore that arises immediately bellow the apical cell of the existing conidiophores.

\section{Mycoherbicidal efficiency of $C$. gloeosporioides}

An optimum (8 $\left.\times 10^{7} \mathrm{spore} / \mathrm{mL}\right)$ spore suspension of $C$. gloeosporioides caused severe infection on host weed in vitro. The leaf spot disease was initiated as round to oval straw colored spots with maroon margins at initial stage of spore treated plants (test plants). The typical symptoms were examined on test plants at 3 day after inoculation. No symptoms were observed on control plants treated with sterile distilled water. After $24 \mathrm{~h}$ of incubation, small pinpoint maroon colored spots were examined on the surfaces of the leaves. These minute lesions on leaves were the result of the penetration of the germ tube or infectious structures on host tissue. An infection rate of (79.41 \pm $1.98 \%$ ) was observed at 30 days after treatment (DAT), and the epidemic increased timely with increase of incubation period. The significant $(P<0.05)$ virulence of pathogen in terms of PDI was determined as $55 \pm 3.57 \%, 76.66 \pm 3.17 \%$ and $79.41 \pm 1.98 \%$ on 7,15 and 30 DAT, respectively. The values are represented mean of five replicates and standard error (Table-1). The environmental conditions, like 100\% moisture, temperature, nutrients and incubation period, enhanced the rate of infection on host, and in addition the susceptibility of the host plant and the virulence of the pathogen significantly increased the rate of infection. The increase of incubation time offers the favorable conditions, such as spore germination, the development of long germ tubes and appressoria (infection structures) and the germination of mycelia fragments. C. gloeosporioides (host) pathosystem revealed the virulence of the pathogen as a promising mycoherbicide agent, which was highly potential to cause severe endemic on leaves, petioles, stem and other propagules of the target weed plant. Statistical analysis of the data on the inoculated plants revealed that percent infection was highly significant $(P<0.05)$ at various growth stages of the weed (Table-2). The early stage of the weed plant with 3-6 foliage favours the germination and penetration of the conidia of $C$. gloeosporioides the infective propagules of the pathogen. The destructive damage of leaves and stems was examined on susceptible stage of the weed and caused $100 \%$ mortality of the weed within short period

Table.1 Disease intensity on test plant inoculated with spore suspension $\left(8 \times 10^{7} / \mathrm{ml}\right)$ of Echinochloa crus-galli

\begin{tabular}{|c|c|c|c|}
\hline \multirow{2}{*}{$\begin{array}{c}\text { Days after } \\
\text { Treatment } \\
\text { (DAT) }\end{array}$} & \multicolumn{2}{|r|}{ Disease intensity (DI) } & \multirow{2}{*}{$\begin{array}{c}\text { DI } \\
\text { Scale }\end{array}$} \\
\hline & Control plants ${ }^{a}$ & Test plants ${ }^{b}$ & \\
\hline $5^{\text {rd }}$ Day & no symptoms & + , mild symptoms on $10 \%$ & 1 \\
\hline 10th Day & no symptoms & + , mild symptoms on $20 \%$ & 2 \\
\hline $15^{\text {th }}$ Day & no symptoms &,++ moderate symptoms on $35 \%$ & 3 \\
\hline 20th Day & no symptoms & ++ , moderate symptoms on $59 \%$ & 4 \\
\hline $25^{\text {th }}$ Day & no symptoms & +++ , severe symptoms, enlarged lesions covering $80 \%$ & 5 \\
\hline 30th Day & no symptoms & $\begin{array}{l}\text { Affected leaves became chlorosis and dried up causing severe } \\
\text { defoliation and withering of leaf. }\end{array}$ & 5 \\
\hline
\end{tabular}

a: inoculated with cool sterilized distilled water , b: inoculated with spore suspension of isolate

Table.2 Disease intensity on test plants inoculated with Colletotrichum gloeosporioides inoculum at different growth stages of Barnyard grass.

\begin{tabular}{|c|c|c|c|c|}
\hline \multicolumn{5}{|c|}{ Effect of Tween 20 on biocontrol efficacy of selected fungal biocontrol agents } \\
\hline Fungus biocontrol agents & No. of Days & Without adjuvants & With adjuvant & Control (\%) \\
\hline \multirow{2}{*}{ Colletotrichum gloeosporiodes } & 7 days & $37 \pm 3.07$ & $55 \pm 3.57$ & $3.4 \pm 4.5$ \\
\cline { 2 - 5 } & 15 days & $65 \pm 2.03$ & $76.66 \pm 3.17$ & $5.2 \pm 6$ \\
\cline { 2 - 5 } & 30 days & $78 \pm 1.25$ & $79.41 \pm 1.98$ & $5.2 \pm 6$ \\
\hline
\end{tabular}




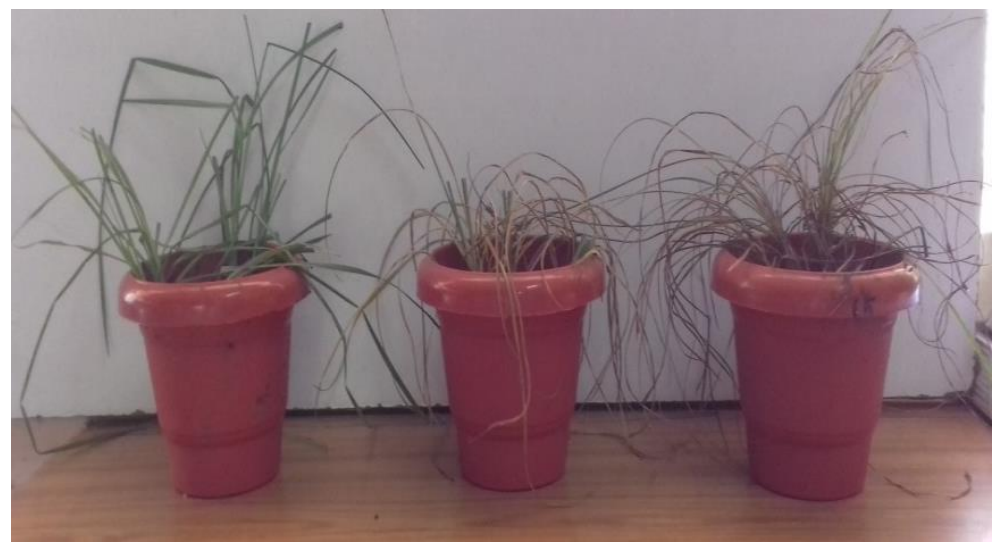

\section{Fig. 1. Effect (infected plants) of colletotrichum gloeosporioides, on Echinochloa crus - galli}

The present data suggest that Colletotrichum gloeosporioides was approved as highly aggressive towards control of Barnyard grass and has certain characteristics suggested by various workers. Barnyard grass is one of most noxious limiting factors in rice production in the world. Colletotrichum gloeosporioides was highly pathogenic on this weed and very safe to rice. The results of this study indicated that this strain could be a potential mycoherbicide to control barnyard grass in the future. There are several biological and environmental limitations which obstruct the efficacy of a biocontrol agent. In the present days, advances in adjuvants formulation and delivery system have been used to overcome some of these limitations and improve the efficacy of a bio-control agent (Boyette et al., 1996).

\section{CONCLUSIONS}

Microbial pesticides (bioherbicides/ mycoherbicides) for the management of weeds are host specific, inexpensive and eco-friendly approaches. There has been a great number of naturally occurring fungal strains investigated for possible use as mycoherbicides, but only a small proportion has been developed to commercial products. The findings in this paper enlightened the mycoherbicide properties of Colletotrichum gloeosporioides and concluded that it is an effective bio control agent to the target weed. The results also revealed that the Barnyard grass weed was controlled by the fungal pathogen $C$. gloeosporioides at field as well as in greenhouse conditions. The fungal pathogen $C$. gloeosporioides is highly virulent as well as host specific. The quantitative data on disease severity revealed the bio control potential of $C$. gloeosporioides as a successful mycoherbicide. The more extensive work is required to study pathogenicity, adaptability and dispersal and survival efficiency of the pathogen for the development of a commercial mycoherbicide. Type of strain and its virulence, variability in spore size and internal nutrients, spore hydration rate, spore adhesion to plant parts, the number of germ tubes per conidia, germ tube lengths, infection structures produced by germ tubes, the number of appressoria per conidia, penetration of plant parts, toxin productions, inoculum adjuvants such as surfactants, interaction with other phylloplane microbes, etc, can affect the successes of a particular fungal isolate. The research in the direction of the development of mycoherbicide based on several field applications should be needed, and also the exploration of different virulent strains of $C$. gloeosporioides is obligatory to develop a successful mycoherbicide.

\section{REFERENCES}

1. Akhtar, K. P., Sarwar, N., Saleem, K., Ali, S. Gibbago trianthemae causes Trianthema portulacastrum (horse purslane) blight in Pakistan. Plant Dis. 2013; 8(1): 109-110.
2. Aneja, K. R., Kaushal, S. Occurrence of Gibbago trianthemae on horse purslane in India. J. Biol Control. 1998;12:157-159.

3. Aneja, K. R., Khan, S. A., Kaushal, S. Management of horse purslane (Trianthema portulacastrum L.) with Gibbago trianthemae Simmons in India. In: Proceedings of the 10th International Symposium on Biological Control of Weeds. 2000; pp.27-33.

4. Balyan RS, Malik PK. Control of horse purslane (Trianthema portulacastrum) and barnyard grass (Echinochloa crus-gali) in mung bean (Vigna radiata). Weed Sci. 1989; 37:695-699.

5. CABI. Echinochloa crus- galli (barnyard grass) invasive species compendium http://www. Cabi. Orrg/ isc/ datasheet/20367 accessed (29 january 2016)

6. Chaube, H. S., and Singh, U. S. Plant Disease Management: Principles and Practices. CRC Press, 1991.

7. Chen, W.C., Yen, J.H., Chang, C.S. and Wang, Y.S. Effects of herbicide butachlor on soil microorganisms and on nitrogenfixing abilities in paddy soil. Ecotoxicology and Environmental Safety. ,2009;72(1):120-127

8. Fu Z W, Zhang C X, Qian Y X. Determination of butachlor resistant Echinochloa crus-galli occurring in paddy rice and study of the resistant mechanism. 2001; 488-493.

9. Holm L, plucknelt D, Pancho J, Herberger J. The world's worst weed: distribution and biology Honolula (H1): university of Hawaii press.1977;609.

10. Kuan, C.Y., Ann, L.S., Ismail, A.A., Leng, T., Fee, C.G. and Hashim, K. Crop loss by weeds in Malaysia. Proceedings of $3^{\text {rd }}$ tropical weed science conference. 1990; 1-21.

11. Leong, K.H., Benjamin, L.L.T, and Mohd Mustafa, A. Contamination levels of selected organochlorine and organophosphate pesticides in the Selangor River, Malaysia between 2002 and 2003. Chemosphere. 2007; 66: 1153-1159,.

12. Maneechote C. Echinochloa control in rice: case study in Thailand. In: Kim K, Labrada R, eds., Echinchloa Control in Rice. Jungkack-Dang Press, Daegu, Korea. 2003; pp. 17-20.

13. Maun, M.A. and Barrett, S.C.H. The biology of Canadian Weeds Echinochloa crus-galli (L.) Beauv. Can. J. Plant Science. 1986; 66: 739-759.

14. Mitchell, J. K. Gibbago trianthemae, a recently described hyphomycete with bioherbicide potential for the control of horse purslane (Trianthema portulacastrum L.). Plant Dis. 1988; 72: 354-355.

15. Pajon, C.M.G. and I.G. Collado. Secondary Metabolites Isolated from Colletrotrichum spp. Prod Rep. 2003; 20: 426-431.

16. Ray, P. and M. P. Hill.. Impact of feeding by Neochetina weevils on pathogenicity of fungi associated with water hyacinth in South Africa. J. Aquat. Plant Manag. 2012;50:79-84

17. Sangakkara, U.R., Sarath, P.N., Marambe, B., Hurle, K. and Rubin, B. Weeds, herbicide use and resistance in rice field of Sri Lanka. Proceedings of the 4th international crop science congress. 2004.

18. Simmons, E. G. "Gibbago, a New Phaeodictyoconidial Genus of Hyphomycetes." Mycotaxon 27: 107-11, 1986.

19. Zhang W M, Moody K, Watson A K. Responses of Echinochloa species and rice (Oryza sativa) to indigenous pathogenic fungi. Plant Disease. 1996; 8: 1053-1058. 